\title{
Orientalización del mundo a través de la cultura Hallyu y la construcción de marca. Caso de estudio Lee Min Ho
}

\author{
Leonor Cremayer Mejía ${ }^{1}$ \\ Universidad La Salle Ciudad de México
}

\section{RESUMEN}

Parte del éxito del fenómeno surcoreano Hallyu se debe a la creación asertiva de marca de cada uno de sus talentos artísticos, a los cuidados procesos de producción de sus productos de entretenimiento, a los nuevos medios de comunicación, y a la participación y el trabajo en redes que hacen los fans. Lee Min Ho es una de las figuras más populares del Hallyu, por ello es un caso para analizar desde la perspectiva documental y de campo. La intención es aportar información con miras a consolidar una línea de investigación en torno a los estudios sobre la orientalización del mundo.

Palabra clave: globalización, orientalización, Hallyu, marca, Lee Min Ho

\begin{abstract}
Part of the success of the South Korean phenomenon Hallyu is due to the assertive brand creation of each one of its artistic talents, the careful production of its entertainment products, the new mass media and the participation in social networks made by the fans. Lee Min Ho is one of the most popular figures in Hallyu. It is important to analyze bim from a conceptual and in field perspective. The intention is to provide information with views to consolidate a line of research around studies about the orientation of the world.
\end{abstract}

Keywords: globalization, orientalization, Hallyu, brand, Lee Min Ho ${ }^{1}$ Maestra en Educación Superior, académica en la Licenciatura en Ciencias de la Comunicación en la Universidad La
Salle Cuidad de México. Correo electrónico: lcremayer@yahoo.com.mx 
ENTRE LA GLOBALIZACIÓN Y LA ORIENTALIZACIÓN

La globalización es una categoría de análisis recurrente, incluso para algunos desgastada, sin embargo, si alguien tiene intención de acercarse a comprender el mundo contemporáneo no puede ignorarla puesto que la globalización tiene impacto en la vida cotidiana y en los hechos que suceden a nivel mundial. No es aventurado decir que prácticamente en todos los campos y en todos los países se ha tenido aproximación con la noción, por lo tanto el concepto forma parte de las agendas de investigación.

La globalización como concepto rector de análisis, se ha aplicado a innumerables objetos de estudio, debido a su persistencia, puede que en algunas ocasiones se presente con poca claridad y en otras provoque posturas en su contra. Hablar de globalización implica analizar al mundo desde la occidentalización y más específicamente desde la norteamericanización.

Giddens refiere que:

La globalización está reestructurando nuestros modos de vivir, y de forma muy profunda. Está dirigida por Occidente, lleva la fuerte impronta del poder político y económico estadounidense y es altamente desigual en sus consecuencias. Pero
Leonor Cremayer Mejía

la globalización no es sólo el dominio de Occidente sobre el resto; afecta a Estados Unidos igual que a otros países (Giddens, 2007, p. 5).

La globalización tiene varios rasgos distintivos, uno de ellos, el que interesa en este texto, es que las tecnologías de información y comunicación juegan un papel de vital importancia, pues el efecto mediático que de ellas deriva ejerce una poderosa penetración cultural que se manifiesta en: el predominio e imposición del inglés como lengua universal, el uso del dólar, el consumo internacional de algunas marcas y la adquisición de pautas culturales y patrones de comportamiento desencadenados por la industria y los contenidos de entretenimiento principalmente manufacturados en Estados Unidos.

Giddens también habla de los fenómenos de colonización a la inversa, por ejemplo, la presencia de culturas que al parecer son minoritarias ante la dominación de la globalización pero que surgen e impactan a otros países y a otras culturas, incluso a la norteamericana. Para Giddens la globalización es motivo del nacimiento de identidades locales en distintas partes del mundo.

No obstante lo anterior, la visión es unilateral si se toma en cuenta que la colonización actual se da únicamente en un sentido, por tanto, 
ver a la globalización como un proceso en una sola dirección, es parcial; recientemente en el mudo se están presentando otros procesos de hibridación cultural protagonizados, por ejemplo, por la industria del esparcimiento asiática; caso concreto de este estudio, Corea de Sur.

La investigación siempre está en constante movimiento y otras miradas de análisis también pueden alternar en los escenarios y en los temas de discusión académica, por ejemplo, la noción de la orientalización del mundo.

El Oriente no es un imaginario, es parte de la civilización. El orientalismo representa y exhibe desde una perspectiva cultural e ideológica una forma de discurso sostenido en algunas instituciones, un vocabulario, imágenes, estilos de enseñar, doctrinas, burocracia y formas coloniales.

En contraste, el conocimiento que Estados Unidos posee sobre el Oriente, al parecer es menos profundo; sin embargo, los contenidos japoneses, coreanos e indochinos están visibilizando lo oriental de forma más académica. Cabe destacar que el incremento de la expansión política y económica de Estados Unidos a Asia también ha favorecido la apertura y conocimiento de la región.

Hablar de orientalismo refiere a múltiples aspectos interrelacionados entre sí. La acepción más aceptada sobre orientalismo es la académica y el concepto se usa para designar a instituciones que desde la antropología, la sociología, la historia o la filología enseñan, escriben o investigan de manera general o específica sobre el Oriente.

A los estudiosos sobre el Oriente se les llama orientalistas y lo que hagan o investiguen se conoce como orientalismo. Para algunos investigadores este término resulta autoritario e impreciso y por eso ciertos especialistas prefieren adherirse al campo de "Estudios orientales" o "estudios de áreas culturales"; no obstante lo anterior, el ámbito del orientalismo está presente en el mundo académico y de la investigación a través de sus doctrinas y tesis acerca del Oriente y lo oriental. El orientalismo es una forma de discurso.

Said dice que:

El orientalismo se puede describir y analizar como una institución colectiva que se relaciona con Oriente, relación que consiste en hacer declaraciones sobre él, adoptar posturas con respecto a él, describirlo, enseñarlo, colonizarlo y decidir sobre él: en resumen, el orientalismo es un estilo occidental que pretende dominar, reestructurar y tener autoridad sobre Oriente (Said, 2008, p. 21).

El fenómeno Hallyu está teniendo una presencia más constante en los foros académi- 
cos, en este sentido se convierte en un objeto de estudio desde la mirada del orientalismo. Es interesante explorar otros marcos teóricos para abordar temas de análisis que son una realidad y que las referencias recurrentes de estudio dan una interpretación sesgada. Los fenómenos de comunicación producidos en Asia abren la puerta para configurar una comunidad de orientalistas.

\section{ACERCAMIENTO AL FENÓMENO HALLYU}

Se conoce como fenómeno Hallyu, cultura Hallyu u ola coreana (korean wave) al efecto provocado por diversos contenidos de entretenimiento producidos en Corea del Sur; entre ellos se encuentran el K-Cine, el K-Pop y el KDrama. Algunas de sus características principales son: ser grandes y costosas producciones, tener temáticas innovadoras, ser distribuidas por medios de comunicación tradicionales y hacer uso de los nuevos medios, particularmente las redes sociales y las plataformas digitales. Otro de los rasgos distintivos es que los fans tienen una intensa participación y actividad en redes sociales, lo cual hace que el impacto del fenómeno haya llegado a los lugares más lejanos y haya tenido los efectos menos pensados.
Un claro ejemplo de lo anterior es la reciente entrega de los Billboard Music Awards 2017, en donde el grupo de K-Pop BTS ganó el premio al Mejor Artista en Redes Sociales por haber logrado 300 millones de votos. Entre los nominados al premio se encontraban Justin Bieber, Selena Gómez, Ariana Grande y Shawn Mendes.

Dal Yong Jin (2016), en su texto New korean wave. Transnational cultural power in the age of social media, aporta la siguiente descripción sobre el Hallyu:

A principios del siglo XXI, la cultura popular coreana se ha convertido en una sensación global. Muchas formas de cultura, incluyendo programas de televisión, películas, música, y animaciones han entrado en el mercado cultural de occidente. Incluyendo América del Norte y Europa. Mientras que la influencia de la cultura occidental, incluyendo las películas de Hollywood, continúa en mercados culturales no occidentales, las industrias culturales coreanas, han expandido la exportación de su cultura a diferentes partes del mundo. Los medios de comunicación; y redes sociales como Facebook y las que tienen contenido aportado por los usuarios como YouTube, han jugado un papel muy importante ya que son las principales plataformas usadas por la cultura coreana popular. La cultura popular coreana está al alcance 
de prácticamente todo el mundo mediante sus programas de televisión y música, muchos fans en todo el mundo disfrutan de esta cultura. La tecnología digital y la cultura, como juegos de video, y teléfonos inteligentes; también han jugado un papel muy importante debido a su sustancial penetración en los mercados globales, estos niveles de éxito en la exportación cultural y tecnológica no es algo que se haya materializado para otros países no occidentales (Dal, 2016, p. 3).

En el texto referido Dal Yong Jin recupera de Joo (2011) y Youna Kim (2013), la siguiente idea:

No tiene mucho tiempo que Corea del Sur comenzó a emerger como uno de los centros de producción de cultura popular. Desde finales de los 90, las industrias coreanas han desarrollado muchos de sus productos culturales exportándolos al Este y Sureste de Asia. Corea se ha convertido en una fuerza local de producción de cultura popular transnacional exportando sus productos en los países asiáticos. El repentino crecimiento de la cultura popular coreana y su diseminación en los países asiáticos, conocidos como la onda coreana, o Hallyu, tomó a muchos países asiáticos por sorpresa, ya que generalmente recibían materiales culturales de EUA, Japón o Hong Kong (Dal, 2016, p. 4).
El autor mencionado concluye que a pesar de ciertas reservas de los medios y de los investigadores quienes han expresado que la ola Hallyu no tendrá largo tiempo de vida dada la protección que ciertos países asiáticos como China tienen con su cultura, el fenómeno coreano se ha propagado a muchas regiones del mundo.

Según la página Korea.net, para el 2013 se contaba con 978 clubes de fans en 78 países, con un total de nueve millones de miembros. En cuestión de regiones, en Asia y Oceanía había 234 clubes (con 6.8 millones de fans). En América 464 clubes (con 1.25 millones de integrantes). En Europa 213 (con 1.17 millones de simpatizantes), en Medio Oriente y África 76 clubes (con 60 mil). Cabe señalar que la mayor parte de estos clubes eran simpatizantes del K-Pop; también hay simpatizantes de los K-Dramas, ídolos, comida, idioma, turismo y cultura en general.

Los contenidos de entretenimiento, las tecnologías de información y comunicación y los nuevos medios, principalmente las redes sociales, han potenciado al Hallyu y han favorecido la configuración de un significativo y muy activo fandom; ${ }^{2}$ hay presencia del Hallyu en Oriente, Oriente Medio, Europa, Norte-

${ }^{2}$ Se llama fandom a un grupo de fans de algo o alguien, significativamente muy entusiastas. 
américa y Sudamérica. Los públicos de la ola coreana pertenecen a diversos segmentos de mercado, no hay un perfil único de seguidores, pero sí hay un motivo de convocatoria común: el interés por conocer y acercarse a la cultura de Corea del Sur.

Conciertos, reuniones con fans (fanmmet), uso de aplicaciones, presencia en todas las redes sociales, dramas de televisión producidos con gran calidad y amplios presupuestos, acceso a contenidos por variadas plataformas, publicaciones en línea, productos de consumo derivados de los personajes de las series y los ídolos en general, videochats con fans, fotos, memes, productos de belleza, tendencias en maquillaje y moda, videoblogs, blogueros, vocabulario, sitios web, aplicaciones para hablar el idioma, incluso comida y bebidas (en algunas partes del mundo los restaurantes y la gastronomía coreana está empezando a ganar terreno), festivales de música y cultura coreana, por ejemplo en K-Con, ${ }^{3}$ entre otros ejemplos más, son los puntos de encuentro que los fans están tomando para apropiarse de un espacio y legitimar una identidad.

En el mundo se está presentando una importante reconfiguración de las formas en

${ }^{3} \mathrm{~K}$-Con es un festival/convención Hallyu que se lleva a cabo en diferentes lugares del mundo. Inició en el 2012 y se ha celebrado en París, Abu Dhabi, Japón y este año se realizó en México. que las audiencias gestionan su esparcimiento, es decir, qué eligen consumir, cómo, cuándo, dónde y por qué medio y/o dispositivo lo hacen. La participación en redes sociales es muy activa, ya que por este medio es que se comparte y se construye una comunidad que busca más que solo ser observadora. Sin embargo, todo lo anterior no sería posible si no estuviera detrás de cada figura del espectáculo la construcción de una buena marca que aporte identidad y que sea símbolo de prestigio y reputación para la audiencia. Park Jin Young fundador de la agencia coreana JYP Entertainment dice que "el éxito de sus artistas radica en que a cada uno se le construye una marca".

\section{EN TORNO A LA CREACIÓN Y GES- TIÓN DE MARCA}

Joan Costa aporta la siguiente noción sobre marca:

La marca es una realidad compleja y global. Es el todo y las partes. No es una cosa ni una superposición de cosas y acciones. La marca es ambivalente: consta de un aspecto real y económico [es el principal capital de la empresa] y un aspecto ideal y cultural [la fascinación social por las marcas y el deseo de apropiación que ellas suscitan]. Este último aspecto es el que determina, en las 
empresas, las decisiones y las estrategias creativas y de gestión de las marcas. Hasta tal punto que ello ha dictado una nueva ley: Diseñar el deseo antes que el producto (Costa, 2012, p. 21).

Desde la teoría y la práctica, la marca es una elaboración estratégicamente planeada, diseñada y gestionada.

La forma en que se vincula a través del lenguaje con el público es primordialmente simbólica y emocional. Objetos, acciones y símbolos (signos, sensaciones, relaciones, imágenes y relatos), son elementos poseedores de significados.

El discurso de la marca se construye en dos niveles: en el real y en el ideal, lo cual provoca un impacto en las personas y en la sociedad. Joan Costa propone los siguientes componentes presentes en la construcción de marca:

1. Lo que la marca hace, es decir, los productos o servicios que son para la compañía el centro del intercambio económico. También es relevante situar lo que la marca es para el público, o sea, los beneficios útiles y emocionales que ofrece a los usuarios.

2. El cómo la marca bace lo que hace y la forma en que lo comunica a sus públicos, se refiere a la presentación, distribución, venta, comunicación y relaciones; es decir, lo que dice, la ma- nera en que lo dice, lo que vende, cómo lo vende y en el lugar donde lo hace.

3. El significado de la integración de los elementos anteriores, lo cual se resume en: público, mercado y sociedad.

El resultado y efecto de lo anterior estriba en la importancia creciente en orientación descendente del punto 1 al 3. En otras palabras, el producto o servicio, con el paso del tiempo, es menos importante que las formas en que se comunica a los públicos, y esto a su vez es menos determinante que lo que el público valora y entiende de la marca. En conclusión, el factor 3 determina a los factores 1 y 2.

Se dice que este proceso es ambiguo, no resuelto, incluso puede tener duplicidad, pues una parte de la construcción de la marca la hace la empresa y la otra el público. La imagen que construye el público está en sus mentes y al ser socializada se comparte en una memoria social, así la marca se concreta a nivel cognitivo en la audiencia y motiva conductas relacionadas con la marca, con esto se consolida el intercambio económico con la empresa y como resultado se logra la creación de valor de la marca.

El significado de la marca es la mezcla de la estrategia de la empresa (posicionamiento), 
las acciones para implementar la estrategia (comunicación) y la representación mental producto del procesamiento psicológico que hace la audiencia (imagen). La imagen de la marca es la consecuencia de haberla dotado de los elementos que cumplen con las expectativas, aspiraciones, autoimagen, estilo de vida y el marco de valores que gobiernan la conducta individual.

El proceso de la creación y gestión de marca está compuesto por el emisor y el receptor. El emisor es representado por la empresa, quien tiene la iniciativa y toma el riesgo de comenzar el proceso de creación y gestión de marca. La empresa debe investigar, balancear la razón y la emoción para lograr la justificación objetiva de la marca y el diseño; dice Costa que esto es "deseo antes que producto". El receptor es el público con un papel activo invisible, es el inductor y condicionante de la iniciativa de la empresa.

El equilibrio entre la actitud de la empresa frente a la planeación de la marca, es una situación balanceada que vincula las razones objetivas de la marca y su diseño. Por lo anterior es preciso plantearse la misión de la marca en respuestas honestas y cabales; el propósito es explicitar cómo la marca, en un mundo de tantas marcas se justifica de manera amplia.
Joan Costa en su artículo "Construcción y gestión estratégica de la marca", recupera a Kapferer con su propuesta de seis cuestionamientos autocríticos en el proceso de creación de marca, los cuales enfatizan lo ya explicado:

1. ¿Cuál es la visión que inspira la visión de la marca?

2. ¿Cuál es su intensa necesidad?

3. ¿Qué pretende modificar en el mercado y qué beneficios desea aportar a los consumidores?

4. ¿De qué coraje y de que fuerzas se dispone para transformar esa utopía en realidad?

5. ¿Qué valores ofrece compartir con sus clientes?

6. ¿Cuál es su compromiso social?

Con base en los puntos anteriores, a continuación se presenta un análisis de la marca de una de las figuras más prestigiadas y queridas del Hallyu, el actor, modelo y cantante Lee Min Ho.

DESCRIPCIÓN Y ANÁLISIS DE UNO DE LOS CASOS MÁS EXITOSO DE CONSTRUCCIÓN Y GESTIÓN DE MARCA DEL FENÓMENO HALLYU: LEE MIN HO

El proceso para la realización del análisis consistió en investigar en diversas fuentes, princi- 
palmente en línea (portales, páginas web, perfiles de Facebook, otras redes sociales y publicaciones especializadas, entre otras). También se realizó un seguimiento a toda la producción audiovisual y campañas publicitarias en las que ha participado el actor durante 11 años de carrera profesional formal. Por otro lado se aplicó una entrevista con dos de las dirigentes de uno de los clubes de fans en México y se dio seguimiento a los comentarios en las redes sociales y otras publicaciones en línea. Por último se realizó el análisis cruzando las categorías propuestas por Joan Costa en cuanto a los componentes de la creación de marca y los datos recabados de las fuentes señaladas y las entrevistas:

Lee Min Ho, nació en Seúl, Corea del Sur, el 22 de junio de 1987. Se le apoda Oppa piernas largas o Minoz: Hace 20 años el actor, modelo y cantante se interesó por el ámbito del entretenimiento, fue entonces cuando se unió a Starhaus Entertainment y comenzó a tener pequeñas participaciones en diversas series de televisión. Desde mayo de 2016 pertenece a la agencia MYM Entertainment. ${ }^{4}$ También es representado por IMX Inc. en

${ }^{4} \mathrm{La}$ agencia MYM Entertainment es administrada por su hermana mayor Lee Yoon Jung y el CEO Starhaus Entertainment Jang Young Hoon.
Japón y Huayi Brothers Media Corporaton en China.

Lee Min Ho tiene estudios en Arte Cinematográfico por la Universidad de Konkuk; es considerado el actor coreano más cotizado y el de mayor fama de la ola coreana en Asia y en el mundo; tiene presencia en Japón, China, Europa, Estados Unidos, América Latina y la mayoría de los países de Asia. Cuenta con millones de fans en todo el mundo, lo cual le ha valido en título de "estrella Hallyu". No hay posibilidad de tener una cifra oficial, pero el conteo que algunas fuentes interesadas en su imagen han hecho a través de sus redes sociales reporta que se estima que tiene un promedio de 17 millones de seguidores en Facebook, lo cual lo convierte en la celebridad coreana con mayor número de seguidores. Lee Min Ho es el primer actor Hallyu en llegar a 20 millones de seguidores en su cuenta Weibo.

Se considera que en el 2006 comenzó su carrera de manera formal; recientemente celebró su aniversario número 11 como actor profesional. Sus clubes de fans en todo el mundo participaron de la celebración generando mensajes de felicitación que fueron compartidos a través de las redes sociales más importantes de Oriente y Occidente.

Es parte de los ídolos que han contribuido a fortalecer la imagen de su país debido a la extensión del entretenimiento surcoreano hacia el resto del mundo. También es uno de los rostros más 
solicitados por las marcas de productos para ser su imagen de promoción. Desde 2009 a la fecha todos los proyectos en los que ha colaborado son éxitos, por ello se le ha apodado El rey Midas coreano. Hasta el año pasado el actor cobraba por episodio de K-Drama alrededor de 58 mil 700 dólares, y durante los primeros tres meses del 2017 ha ganado 1.34 millones de dólares.

En el 2009 llegó su oportunidad y con ella el gran éxito de la empresa KBS: ${ }^{5}$ el K-Drama Boys over flowers, ${ }^{6}$ en donde interpretó el papel Gu Jun Pyo. Gracias al impacto de la producción el actor ganó popularidad y fans, este fue el origen de su éxito a nivel mundial. En el año 2012 logró el puesto de mejor estrella Hallyu en una revista japonesa centrada en los K-Dramas. Es considerado integrante de la segunda generación de estrellas Hallyu masculinas del cine y la televisión.

Desde el 2009 se interesó en apoyar causas sociales y en el 2014 creó la plataforma web llamada PROMIZ con el objetivo de fomentar donaciones con sentido social. Se dona el 100\% re-

${ }^{5}$ Korea Broadcasting System (KBS) es una empresa de radiodifusión que agrupa los servicios públicos de radio y televisión de Corea del Sur. Entre sus contenidos se encuentran dramas, deportes y documentales. Cuenta con el portal (KBS Global) un canal de YouTube, la aplicación KBS World y otros servicios. ${ }^{6}$ Boys over flowers fue producido en el año 2009, la historia está basada en un manga japonés. Es el K-Drama más visto en todo el mundo y actualmente está disponible en varias plataformas de entretenimiento, como DramaFever, Viki y Netflix. caudado de los múltiples proyectos y los ingresos de las ventas de diversos productos. Los clubes de fans Minoz a través de todo el mundo han estado colaborando en la construcción de la cultura de compartir con los que más lo necesitan. Algunos de los proyectos son: creación de bosques, preservación del medio ambiente, actividades de voluntariado y trasferencia de fondos. Desde el inicio de la plataforma la cantidad de donaciones ha sido de 400 millones de wons en tres años. Uno de los proyectos importantes con los que ha colaborado es con UNICEF (Holt Children's Welfare Division and Good Neighbors).

Lee Min Ho es el único artista en el campo de la cultura popular que en mayo del 2016 obtuvo El Premio a la Buena Marca, el reconocimiento fue seguido por First Happiness Sharing Improvement y en el 2017 ha sido seleccionado nuevamente como ganador de la Marca de Cultura Award del Premio Nacional de la Marca. La selección la hizo la Agencia Nacional de Promoción de la Marca de Corea del Sur en reconocimiento al mérito social de practicar valores de buena voluntad y compartir con todo el mundo.

Entre sus enlaces se encuentran: páginas oficiales (Corea y Japón), perfil oficial (agencia), plataforma PROMIZ, Twitter oficial, Facebook oficial, YouTube oficial, Instagram oficial y Weibo oficial. ${ }^{7}$ Sus redes sociales son: Facebook Official

${ }^{7}$ Sina Weibo es una red social china. 
(LeeMinho) con 17 millones 553 mil 706 personas que les gusta y 17 millones 367 mil 205 seguidores. Última actualización 31 de marzo de 2017 con una publicación sobre el documental narrado por el actor, Dmz the wild, desarrollado en la zona desmilitarizada entre Corea del Norte y Corea del Sur. Facebook PROMIZ con 62 mil 392 personas que les gusta y 61 mil 887 seguidores. Última actualización 25 mayo 2007 con la publicación sobre el Premio a la Mejor Marca, obtenido por segundo año consecutivo a la Plataforma de Donación PROMIZ. Instagram con 5.8 millones de seguidores y 49 fotos publicadas. Twitter con 3.05 millones de seguidores, está afiliado desde 2010, hay 59 fotos y videos publicados, y su última actualización fue el 31 de marzo del 2017. Canal YouTube dado de alta desde marzo de 2014, tiene dos mil 629 suscritos, hay publicados varios videos y listas de reproducción; el canal está vinculado con el resto de sus redes sociales y su última actualización fue el 12 de mayo del 2017. Por último tiene una cuenta en la red social Weibo con 29 millones cinco mil 374 seguidores, $y$ en Tumblr con una última actualización el 12 de mayo del 2017.

Su participación en K-Dramas se resume en la siguiente lista: The lost empire (KBS 2001); Sharp 1 (2003); Nonstop (MBS 2004); Love Hymn (MBC 20005); Secret campus (EBS 2006); Mackerel run/ I'm Sam (SBS 2007); I'm Sam (KBS 2007); But I don't know (2007); Boys over flowers (KBS 2009); Anycall Haptic Mission 2 (Reallity 2009); Personal taste (MBC 2010); City bunter (SBS 2011); The fait (SBS 2012); The heirs (SBS 2013); Line romance (2014); Summer love (2015); Legend of the blue sea (SBS 2016-2017); 7 first kisses (KST 2016-107).

Entre sus películas están: Repechage (1997); Love (2000); Ghost lives (2004); Arang (2006); Public enemy returns (2008); I don't know too (2008); Our schools E.T. (2008); Gangnam blues (2014); Bouty bunter (2016).

Imagen de marcas: entre 2016 y 2017 ha colaborado para Georgia Gotica Coffee, EIDER, Good Base, Lotte Duty Free Star Avenue, Tanki's Family Whit Star y Seven Luck Casino. En este periodo es imagen del stand de Visit Korea Year del K-CON Japón 2017 y de Coca Cola Korea en Twitter (@CocaCola_Korea).En 2015 trabajó para Ferrero Rocher. Durante 2014 fue imagen de Samsonite RED, Jeju Air (Refresch in Jeju), Innisfree (Merry Green Christmas para Save the Children), Yadea (bicicletas eléctricas), Tenwow (bebidas), Tencent Weishi (mobil app), Suphier (ladies shoes), Romanson (relojes), Pepsi (China), Oozing (education tablet), OSIM uDiva, Taobao Mobile App (China), Lotte Busan Hotel, Lotte Duty Free, Line Messaging App (China), LG Electronics (China), Kyochon Chicken, KIA K3S, Jeju Air, Isun Potato Snack, 
Guess, FILA (China), A twosome Place (coffee China).

En 2013 participó con la empresa de ropa deportiva EIDER y en 2012 colaboró con 12+. En el lapso de 2012 a 2014 continuó con su participación en la compañía Innisfree (cosméticos) y entre 2011-2014 hizo comerciales para Semir (ropa).

De 2011 a 2012 apareció como imagen de Toyota Camry: The One and Only, participó con la empresa Hyundai Veloster DCT y se mantuvo con EIDER. En 2010 trabajó para LG Optimus, Jang in Furniture, Lotte Cantata, Lotte Pie (Vietnam), LG Phone (Sout-East Asia), Binggrae Banana Milk y Bang Bang. Entre 2009 y 2013 participó en la campaña de Trugen. De 2009 a 2010 publicitó a Etude House. En 2009 trabajó con Dunkin' Donuts, Levi Strauss Signature, Orion Market O, LG TeleCom, Samsung Anycall Magic Hole, Cadillac Crossover (ALL-New SRX), Pepsi NEX y $2 \mathrm{X}$ Cass Beer. Por último en 2007 trabajó para Lotte World.

Su discografía es breve y está compuesta por My everything (2009); Song for you (2014); Extreme (2009) The day (2015); Always (2017). Del 2009 al 2016 se presentó en 36 conciertos por Japón, Corea, Tailandia, China, Vietnam, Taiwán, Filipinas, Malasia, Indonesia y Singapur.

Entre sus reconocimientos se encuentran:
2016-2017: por dos años consecutivos la plataforma PROMIZ ha ganado el premio Buena Marca de Corea.

2016: SBS Drama Awards, premios a Mejor Pareja, Top Excellence Award y 10's Star Award, por Legend of the blue sea.

2015: PaekSang Arts Awards, premio al Actor más Popular por Gangnam blues. 1st Beaksang Arts Award, premio a la estrella Hallyu. Korea SNS Industry Grand Award, President Award of National Information Society Agency. 19 ${ }^{\text {th }}$ Bucheon International Fantastic Film Festival Awards, premio al Productor a Elección. 10 $0^{\text {th }}$ Seoul International Drama Awards, premios al Actor más Popular y Top Hallyu. Grand Bell Awards/Daejeon Film Awards, premio a la Popularidad. 36 ${ }^{\text {th }}$ Blue Dragon Film Awards, premio a la Popularidad por Gangnam blues. Korea Turism Awards, premio Estrella del Turismo.

2014: Singapore Entertainment Awards, premio Artista más Popular de la Televisión Coreana. $5^{\text {th }}$ Korean Popular Culture \& Arts Award, Prime Minister Award.

2013: SBS Drama Awards, premios a Mejor Actor, al Mejor Vestido, a la Mejor Pareja y a las Mejores 10 Estrellas por The heirs. Korea Updates Awards, Mejor Actor, Pareja Favorita y Gran Awards-Daesang por The heirs. Baidu Music Award, premio Mejor Actor de Asia por The heirs. 
2012: 1th Drama Fever Awards, premio a Mejor Actor y Mejor Pareja por Faith. SBS Drama Awards, premio Superior a la Excelencia y Premio a las 10 Mejores Estrellas por Faith.

2011: Korea Drama Festival Awards, premios Mejor Actor y Estrella Hallyu por City bunter. SBS Drama Awards, premios Superior a la Excelencia, Actor más Popular y Top 10 Estrellas por City bunter.

2010: MBC Drama Awards, premio a la Excelencia por Personal taste. Mnet 20's Choice Awards, Hot Actor.

2009: Broadcast Advertisment Festival, premio Mejor Modelo Masculino de CF (campaña Trugen). KBS Drama Awards, premio Actor Revelación y Mejor Pareja de Drama por Boys over flowers. 14 $4^{\text {th }}$ Asian Television Awards, nominado a
Mejor Actuación por Boys over flowers. The $45^{\text {th }}$ Beaksang Arts Awards, premio Actor Revelación por Boys over flowers.

En otras distinciones, fue embajador honorario de la campaña Amor Neto de UNICEF para combatir el paludismo (2009-2010). Fue fiscal de honor, embajador de Relaciones Públicas para los fiscales de Corea (2012-2013), de igual manera se le seleccionó como embajador público del Turismo de Corea, también denominado "rostro de Turismo de Corea". Actualmente es embajador honorario de los Juegos Olímpicos de Invierno 2018, que se realizarán en Pyeongchang, y de Visit Korea Year (2016-2018). Algunas imágenes que ilustran parte de lo descrito se muestran en la siguiente página. 


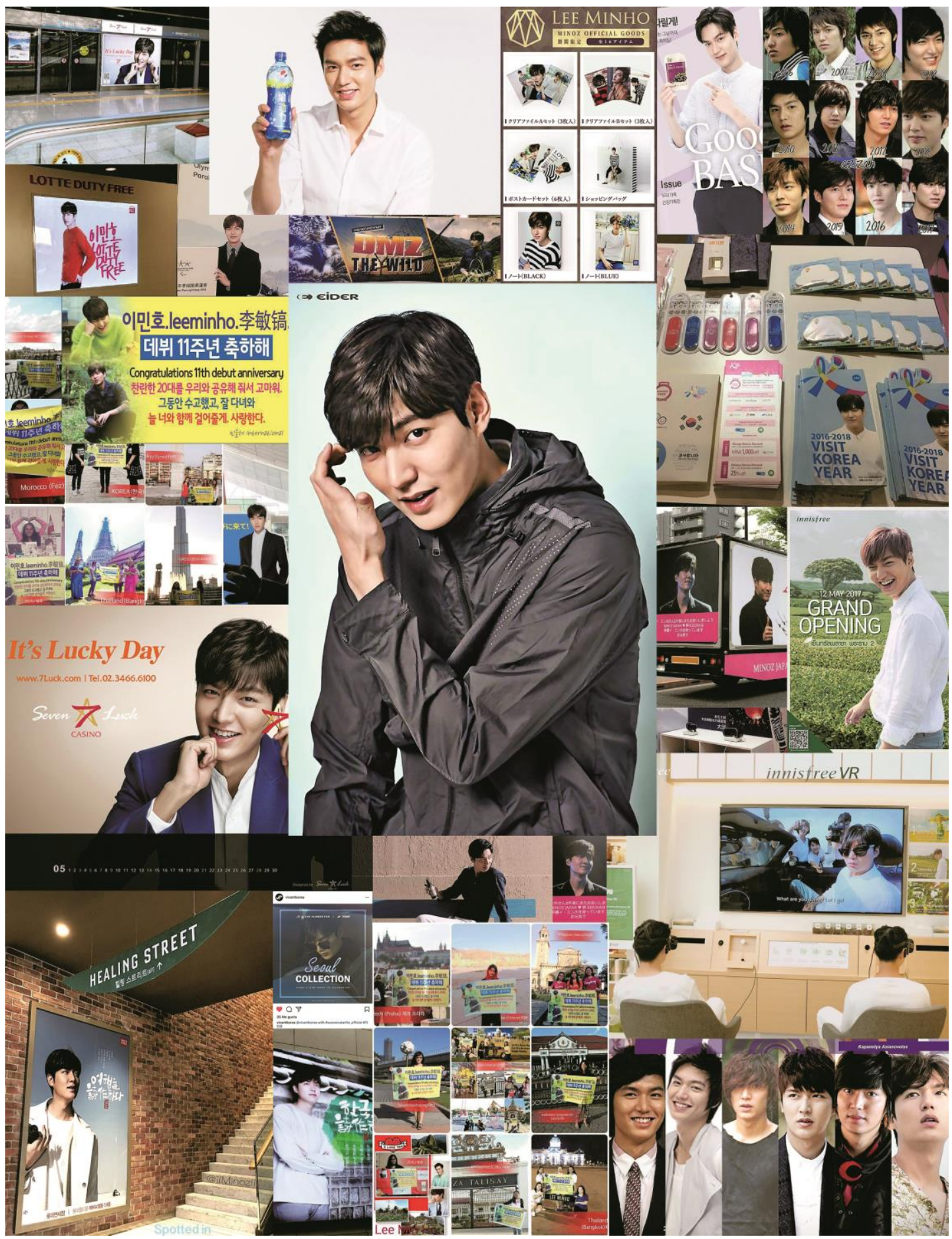

\section{$\because$}


MUESTRA DE LA IMAGEN DE LEE MIN HO APLICADA DIVERSOS PROYECTOS

Para tener un acercamiento con una muestra del público al que va dirigida la marca de Lee Min Ho, se realizó una entrevista con las representantes del club de fans Minoz México Official, Gloria Vanesa Salazar y Rosa María Méndez López. En el mundo solo hay dos clubs oficiales del actor: Minoz Corea y Minoz Japón, sin embargo, existen numerosos clubes de fans en todas partes. El club se eligió debido a que es una de las agrupaciones de fandom más estructurada y con actividades formales, por ejemplo, celebran reuniones, organizan eventos, manejan redes sociales y participan en acciones con causa social. El club tiene perfil de Facebook (Minoz México Official), cuenta de Twitter (@MinozMexOficial)y su sitio web está en proceso de construcción.

En las entrevistas con las dirigentes se aplicaron ocho preguntas para explorar la forma en que se han organizado como club de fans, conocer el tipo de perfil de las integrantes, indagar cómo trabajan y explorar el imaginario que han construido sobre el artista debido a la imagen que transmite. Vanesa y Rosa María señalan que mantienen relación con clubes de fans de todo el mundo (China, Corea, Filipinas, Rusia), el idioma que utilizan para hacerlo es el inglés. Con los clubes en Latinoamérica usan el español.

Con relación a sus fuentes de información para alimentar sus redes sociales las entrevistadas indicaron que éstas provienen de fans de países asiáticos, pues gracias a ellas se filtra la información. También dijeron estar pendientes de las páginas y redes sociales de todas las marcas para las que el actor modela y las redes sociales como Weibo, Twitter y diversos foros. Principalmente usan Twitter, Facebook y Weibo.

En lo que respecta a su forma de organización como club comentan

...entre todas nos apoyamos para publicar; todas tenemos roles específicos y una de nosotras es la principal encargada de las publicaciones en las redes sociales mencionadas. La comunicación entre nosotras es primordial, procuramos subir información reciente, por ejemplo, imágenes, comerciales nuevos, noticias, justamente de los foros en donde muchas veces se publica información en inglés. La información la traducimos para hacerla accesible a las seguidoras. Cuando no hay noticias recientes colocamos contenidos de otros meses o años pasados. Es fundamental para nuestro club mantener la página activa (R.M. Méndez y G.V. Salazar, entrevista 28 de mayo de 2017). 
Con relación a lo que Lee Min Ho representa para las fans las entrevistadas dijeron que: "él es un ejemplo de humildad, inspiración, alegría, amor, fortaleza, nobleza, felicidad y trabajo, además es un gran actor y un hombre apuesto". Señalan que "él les ha mostrado que a través de acciones se puede ayudar a más personas y aportar un grano de arena para hacer este mundo mejor. Sus acciones a través de PROMIZ, nos han inspirado en múltiples formas para ser mejores personas. En varias ocasiones nos han preguntado amigos y demás personas, que qué vemos en él y la respuesta siempre es esa; vemos humildad, a un ser humano agradecido con la vida y con sus fans" (R.M. Méndez y G.V. Salazar, entrevista 28 de mayo de 2017).

Minoz México Official está organizado por cinco administradoras, sus edades están entre los 22 y 40 años. Cuatro de ellas cuentan con estudios universitarios concluidos en Ingeniería, Química, Derecho, Contaduría y Psi- cología, y una integrante aún estudia. En su grupo privado las edades son similares y las ocupaciones van desde amas de casa hasta profesionistas y trabajadoras en diversas áreas.

Finalmente en la pregunta ¿Por qué Lee Min Ho, lo que es, lo que hace y cómo lo hace es tan valioso para ustedes?, las entrevistadas respondieron

...muchas de nosotras hemos expresado que nos encontrábamos en una situación difícil de nuestras vidas cuando lo conocimos y literalmente cambió nuestra vida de una manera positiva, primeramente porque como lo mencionamos se convirtió en un ejemplo de lucha, humildad y amor, también porque conocimos a más personas y juntas creamos lazos de amistad sólidos que sabemos que es difícil que se rompan; por ello es algo valioso para todas nosotras porque por más cursi que suene él inyectó a nuestra vida de felicidad y amor" (R.M. Méndez y G.V. Salazar, entrevista 28 de mayo de 2017). 
A continuación se presenta el cuadro de análisis.

\section{Análisis de la marca Lee Min Ho con base en la propuesta de Joan Costa}

\begin{tabular}{|c|c|}
\hline $\begin{array}{l}\text { Lo que la marca hace } \\
\text { (Posicionamiento) }\end{array}$ & $\begin{array}{l}\text { - Vender la imagen sublimada de un actor, cantante y modelo a un } \\
\text { segmento prioritariamente femenino y popular de Corea del Sur y } \\
\text { del mundo. } \\
\text { - Replantear la masculinidad, la belleza, la estética y la moda asiática. } \\
\text { - A través de su imagen mostrar una sociedad surcoreana que equili- } \\
\text { bra los valores tradicionales, la modernidad y el alto desarrollo tec- } \\
\text { nológico. } \\
\text { - Incrementar el interés del turismo internacional por el destino. }\end{array}$ \\
\hline $\begin{array}{l}\text { Cómo la marca hace } \\
\text { lo que hace } \\
\text { (Comunicación) }\end{array}$ & $\begin{array}{l}\text { - } \text { Participa en proyectos audiovisuales congruentes con su imagen. } \\
\text { - Es imagen de marcas prestigiadas dirigidas a múltiples segmentos de } \\
\text { - } \text { Es actido. } \\
\text { - A través de eventos y presentaciones públicas, tiene acercamiento } \\
\text { - } \text { Inspirante con fans. } \\
\text { - Su para fandom mundial para trabajar a través de las redes socia- } \\
\text { - Tiene trabajo colaborativo con instituciones públicas de su país. }\end{array}$ \\
\hline $\begin{array}{l}\text { Significado de la inte- } \\
\text { gración de los ele- } \\
\text { mentos anteriores } \\
\text { (Imagen) }\end{array}$ & $\begin{array}{l}\text { - Pulcro, impecable, vanguardista, carismático, alegre, positivo, traba- } \\
\text { jador, perseverante, atento, agradecido, preocupado por su entorno } \\
\text { y participativo en causas sociales de su país y del mundo. } \\
\text { - Su imagen es inspiradora y terapéutica. Aporta sentimientos de feli- } \\
\text { cidad a sus fans. } \\
\text { - Es embajador de la cultura coreana a nivel mundial y es motivo de } \\
\text { orgullo nacional. }\end{array}$ \\
\hline
\end{tabular}




\section{CONCLUSIONES}

La creación de marca de cada uno de los talentos artísticos que forman parte de la propuesta de entretenimiento surcoreano es básica para el éxito de sus productos. En poco tiempo el Hallyu se ha extendido a lo largo de todo el mundo y se ha vuelto tema de investigación académica. Lee Min Ho es una de las figuras de mayor prestigio del espectáculo asiático y ha contribuido a incrementar el interés por conocer la cultura, la gastronomía y el idioma de su país.
Los trabajos desde el observatorio de la orientalización del mundo no son nuevos pero si poco frecuentes, situar a la investigación de la comunicación desde otras racionalidades ofrece nuevas lecturas para los objetos de estudio propios del campo.

Finalmente, este artículo tuvo la pretensión de visibilizar una alternativa para agrupar y analizar temáticas de reciente aparición y con ello diversificar los marcos teóricos en el área de la comunicación. 


\section{FUENTES CONSULTADAS}

@ ActorLeeMinHo. (28 de mayo del 2017). Twitter . Obtenido de https://twitter.com/actorleeminho. actorleeminho. (28 de mayo del 2017). Instagram. Obtenido de https:/www.instagram.com/Actorleeminho/.

actorleeminho. (28 de mayo del 2017). Weibo. Obtenido de http://www.weibo.com/actorleeminho.

Costa, J. (2012). "Contrucción y gestión estratégica de la marca. Modelo MasterBrand". En: Luciérnaga, 2025.

Dal, Y. J. (2016). New Korean Wave. Illinois: University of Illinois.

Entertainment, M. (2016). Lee MinHo. Obtenido de http://www.leeminho.kr/front/.

Fandom Powered by Wikia (25 de mayo del 2017). Obtenido de http://es.drama.wikia.com/wiki/Lee_Min_Ho.

Giddens, A. (2007). Un mundo desbocado. México: Taurus.

Korea.Net (28 de mayo del 2017). Obtenido de http://www.korea.net/index.jsp.

Minoz, W. A. (mayo del 2017). Tumbrl. Obtenido de http://weareminoz.tumblr.com/.

OfficialLeeMinho (2017). Facebook. Recuperado el 28 de mayo del 2017 de https://www.facebook.com/OfficialLeeMinho.

PROMIZ (25 de mayo del 2017). Facebook. Obtenido de https://www.facebook.com/pmz2014/

PROMIZ. (28 de mayo del 2017). Plataforma. Obtenido de https://www.minho.jp/pmz/index.html. Said, E. (2008). Orientalismo . Barcelona: Debolsillo.

Visit Korea (28 de mayo del 2017). Obtenido de http://english.visitkorea.or.kr/enu/CU/content/cms_view_860713.jsp.

Visit Korea (28 de mayo del 2017). Obtenido de http://spanish.visitkorea.or.kr/spa/index.kto.

WeRMinoz (28 de mayo del 2017). YouTube. Obtenido de https://www.youtube.com/user/WeRMinoz/feed 